\title{
IMPLANT STABILITY PARAMETERS \& BONE DENSITY VALUES OF DIFFERENT GRAFT MATERIALS WITH IMMEDIATELY PLACED DENTAL IMPLANTS
}

\author{
Omnia I. Sultan*, Ingy M. Chehata** and Ahmed M Hossam***
}

\begin{abstract}
Objectives: This study was conducted to assess and compare the effect of autogenous bone graft versus mineralized plasmatic matrix (MPM) and versus the Nano hydroxyapatite bone graft as bone regenerative materials during immediate implant placement.

Material and Methods: A total of 14 patients with 18 implants have been included in this study, patients were divided into 3 groups. Group I(control group) received autogenous bone graft. Group II (study group A) received Mineralized Plasmatic Matrix (MPM), and group III (study group B) received Nano hydroxyapatite as bone regenerative materials for immediate implant placement. The treatment outcome was evaluated clinically and radiographically at 3 and 6 months of implant placement. Implants stability was measured using Osstell radiofrequency device at 3 and 6 months postoperatively. Also bone density were measured radiographically at 2 weeks and at 3 and 6 months postoperatively and statistically analysed.
\end{abstract}

Results: Statistical analysis of bone density measurements between the three groups showed significant difference $(\mathrm{P} \leq 0.05)$ between the control autogenous bone group and the two other groups (MPM \&Nano bone) at all time intervals. Comparison between the test groups revealed non-significant difference $(\mathrm{P} \leq 0.05)$ between (MPM \& Nano bone) at two weeks interval. While at three $\&$ six months postoperatively there was a significant difference $(\mathrm{P} \leq 0.05$ between the two groups. Regarding implant stability comparison between the three groups , there was no statistical significant difference between them $(\mathrm{P} \leq 0.05)$ at three and six months post operatively.

Conclusion: The autogenous bone graft remains the gold standard for grafting materials but the use of MPM and Nano hydroxyapatite grafting materials can also give successful results regarding implant stability and bone density.

KEYWORDS: Immediate implant, autogenous bone graft, MPM, Nano hydroxyapetite bone graft, bone regeneration, osseointegration, growth factors, platelets concentrates.

* Lecturer of Oral \& Maxillofacial Surgery. Faculty of Dentistry. October University of Modern Sciences and Arts

** Assistant Professor of Oral \& Maxillofacial Surgery. Faculty of Dentistry. October University of Modern Sciences and Arts

*** Lecturer of Radiology. October University of Modern Sciences and Art. Egypt 


\section{INTRODUCTION}

Since Branemark and his colleagues introduced the concept of osseointegration \& its implication in dentistry, implant therapy became an integral part of current dentistry. ${ }^{\left(1^{2}\right)}$ The following years witnessed many researches regarding different materials \& techniques of implants.

Studies performed during the past 20 years have shown great predictability and success for dental implants placed immediately at the time of tooth extraction. ${ }^{(3,4)}$ with high survival rates reaching more than $95 \% .^{(3,5-7)}$ Authors described primary implant stability as a guiding factor for long term success predictability of immediate implants. ${ }^{(1,8)}$

Clinical \& experimental studies reported dimensional changes of the alveolar bone following tooth extraction with varying degrees of vertical \& horizontal bone loss. ${ }^{(9)}$ Although implant placement into fresh extraction socket is thought to reduce bone resorption, studies reported that immediate implant installation failed to interfere with bone remodelling. ${ }^{(10,11)}$ In order to overcome the continued process of ridge contraction many strategies were proposed including immediate implant placement with varying grafting materials $\&$ barrier membranes. Clinical \& experimental reports advocated grafting the gap between immediately placed implant and extraction socket to enhance hard \& soft tissue healing. ${ }^{(12-14)}$ Review article by Chen \& Buser recommended bone augmentation with immediate implants for improved functional \& aesthetic outcomes. ${ }^{(15)}$ Although autologous bone grafts remain to be the golden standard as a regenerative material with unique osteogenic potential. Its inherited limitations due to donor site morbidity \& prolonged surgical procedure advocated researchers to look for alternatives. Recently investigators implied tissue engineering methods to enhance results of bone augmentation with documented effect of growth factors. ${ }^{(16)}$
Autologous plasma rich with growth factors (PRGF) showed potential effect to accelerate healing of hard \& soft tissue around implants. ${ }^{(17,18)}$ Mixing bone graft particles with growth factors produced Mineralized Plasmatic Matrix (MPM). MPM is an autologous blood product with high platelet concentrate \& fibrin prepared in a liquid state $\&$ mixed with a bone substitute. The material become malleable along with adding the effect of growth factors on enhanced bone regeneration. ${ }^{(19)}$ Recent studies supported the use of MPM with immediate implant placement \& showed improved bone regeneration $\&$ implant stability. ${ }^{(20,21,22,23)}$

Variety of synthetic bone substitutes are invented with the new advances in tissues engineering and nanotechnology. Nano bone grafting material is a newly developed graft made of silica gel \& hydroxyapatite nanocrystals in matrix. The rough surface of the nano structure provides porous pattern that resembles the structure of natural bone. ${ }^{(24)}$ Nano hydroxyapatite is believed to be biologically active synthetic grafting material with great biocompatibility with hard \& soft tissues. ${ }^{(25)}$ The biologicalcompatibility of this material along with its osteoconductive property advocated researchers to use it in bone regeneration and implant dentistry. ${ }^{(26-29)}$

Although the primary stability and bone regeneration achieved using different grafting materials around immediate implants are important factors influencing the long term success, the correlation between them is not well evaluated. The aim of the current study is to evaluate the effect of varying grafting materials utilized with immediate implants on implant stability \& bone regeneration.

\section{PATIENTS AND METHODS}

Participants in this study were selected from the outpatient clinic from the Department of Oral and Maxillofacial Surgery, Faculty of Dentistry, October University of Modern Sciences and Arts. 


\section{Sample selection:}

Fourteen patients ( 9 female, 5 males) with mean age of 37 years old (21-53 years old) were included. Subjects enrolled were seeking for replacement of un- restorable or badly destructed teeth with immediate implants. Total number of eighteen immediate implants were installed for replacement of single rooted teeth. All individuals went through detailed clinical examination and radiographic evaluation after taking medical history. Selected subjects were informed about the nature of the study $\&$ written consents were obtained to participate.

\section{Inclusion criteria:}

Included patients were systemically healthy with decent oral hygiene. Presented with one or more unrestorable hopeless single rooted teeth indicated for extraction. With clinical and radiographic data confirming the presence of adequate bone quality \& quantity for initial implant stability.

\section{Exclusion criteria:}

The presence of any local pathology, systemic health status or chronic medications that could interfere with hard or soft tissue healing. Patients with poor oral hygiene and severe periodontitis were also excluded. As well as patients with parafunctional habits and abnormal occlusal relationship that may complicate future restoration.

\section{Patients Grouping:}

Selected individuals included in the present study were randomly divided into three groups:

\section{Group 1 (control group) 6 immediate implants:}

The gap around the implant and the socket wall was filled with autogenous bone graft collected from the chin.

\section{Group 2 (Study group A) 6 immediate implants:}

The gap around the implant and the socket wall was filled with mineralized plasmatic matrix MPM (sticky bone graft).

\section{Group 3 (Study group B) 6 immediate implants:}

The gap around the implant and the socket wall was filled with Nano- hydroxyapatite bone graft.

\section{Surgical technique:}

\section{Implant site preparation:}

Following administration of adequate local anaesthesia atraumatic tooth extraction was carried out with aid of periotome. (Fig1) The socket was then thoroughly debride with small bone curette and irrigated with saline solution. The osteotomy site was prepared using sequential drilling prior to placement of equivalent implant size. After implant installation the gap between the implant \& the socket wall was filed with a grafting material according to the pre-planned patients grouping.

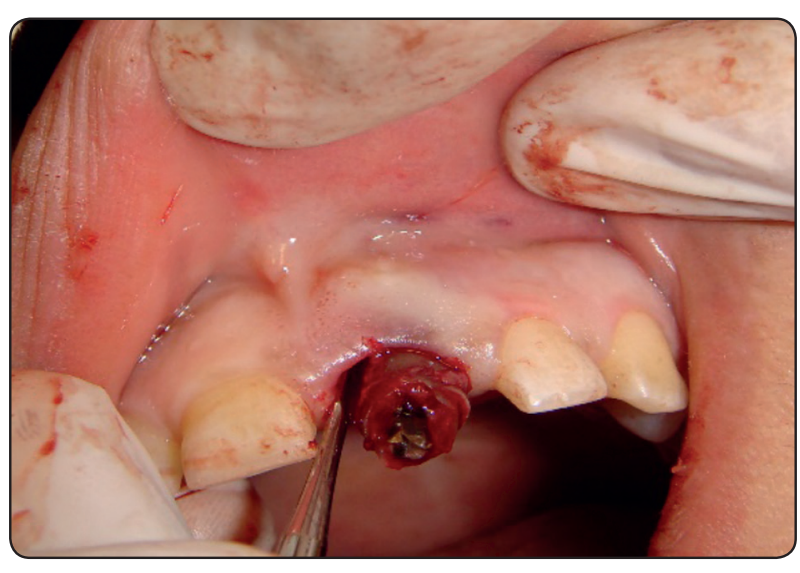

Fig. (1) Showing atraumatic tooth extraction

\section{Graft preparation:}

\section{Group 1 (control group)}

For the control group autogenous bone was collected from chin using $5 \mathrm{~mm}$ diameter trephine drill after reflection of suitable mucoperiosteal flap. The collected bone cores were crushed using bone mill to obtain particulate bone graft. (Fig2 A,B) 


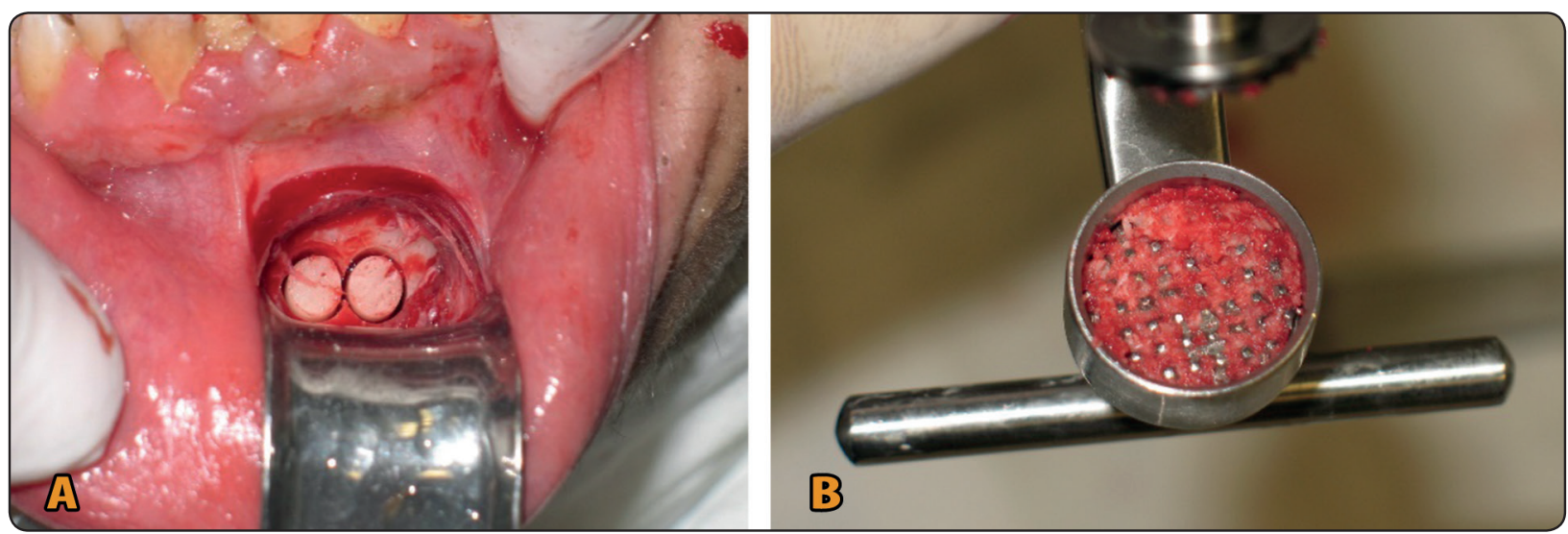

Fig. 2 (A,B) : Showing collected autogenous bone cores.

\section{Group 2 (Study group A)}

According to Dohan et al. ${ }^{(30)}$ protocol for MPM preparation venous blood was taken from the antecubital fossa and transferred to $(10 \mathrm{ml})$ sterile test tubes deprived of anticoagulant. For separation of platelet rich plasma from red blood cells; test tubes were placed in the centrifuge machine operated for 10 minutes at 2700-3000 rpm. After centrifugation three distinctive layers are separated. The bottom one of red blood cells, middle part of platelet rich plasma and upper most layer of platelet poor plasma. Upper and middle parts of each supernatant were collected using syringes. This plasma rich part contains fibrin network with plasma leukocytes and undifferentiated mesenchymal cells. To achieve the sticky bone the collected fibrin combination is mixed with particulate bone graft (Beta tri calcium phosphate $\beta$-TCP) and few drops from the patient blood and allowed to set for few minutes. (Fig3 A,B)

\section{Group 3 (Study group B)}

For this group the alloplastic Nano-crystalline hydroxyapatite NanoBone ${ }^{\circledR}$, ARTOSS $\mathrm{GmbH}$ Company,Rostock, Germany) was utilized to fill the gap between the implant $\&$ the socket wall. The material is mixed with few drops of patient blood. (Fig4 A, B)

After implant placement and grafting procedure the buccal flap is advanced and sutured.

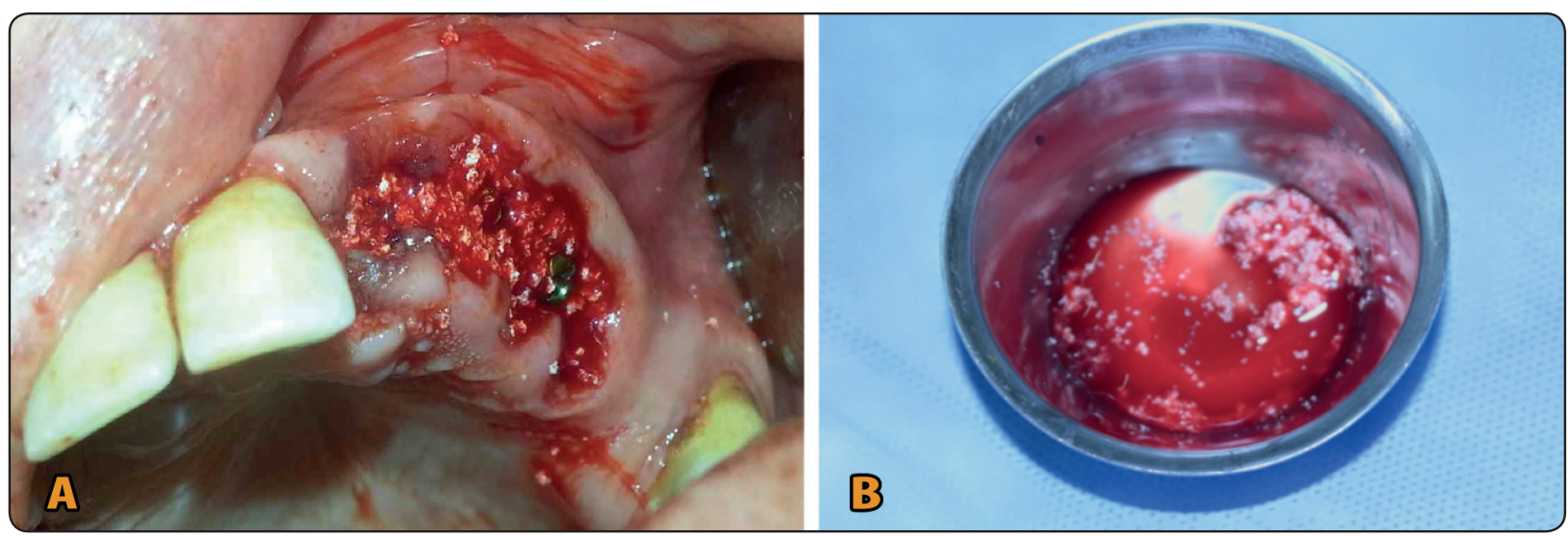

Fig. 3 (A,B) : Showing filling of the gap around the immediate implants with MPM. 


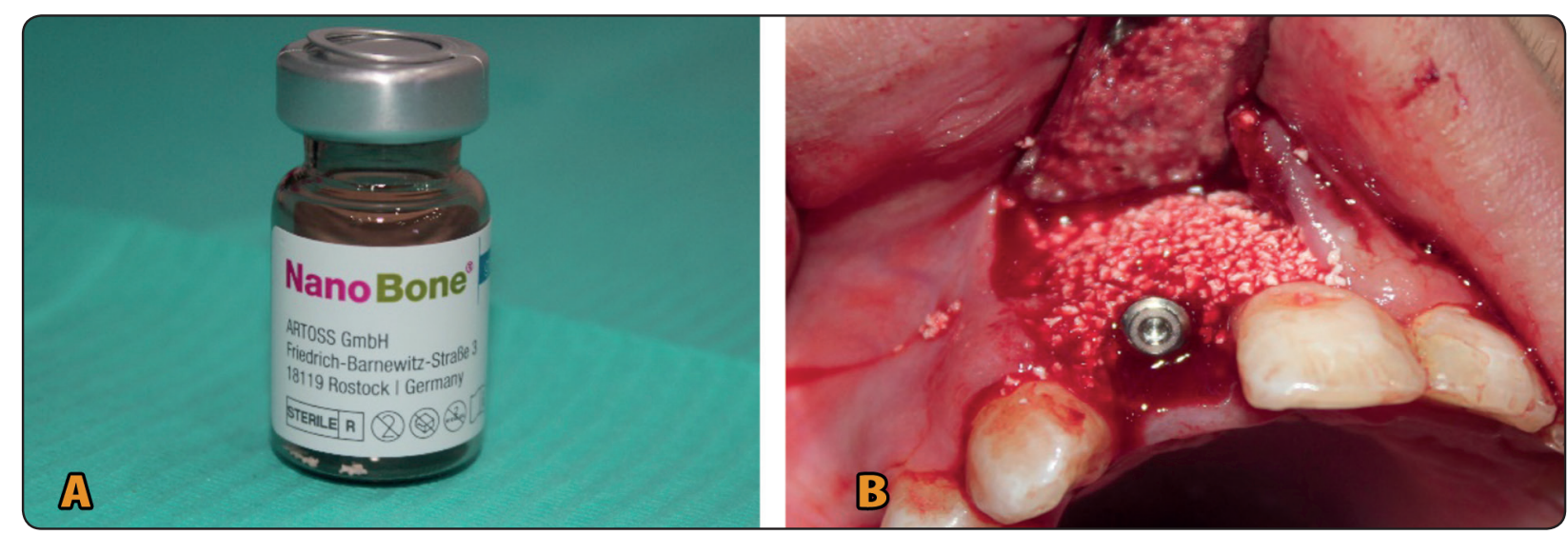

Fig. $4(A, B)$ : Showing filling of the gap around the immediate implants with Nano-crystalline hydroxyapatite.

\section{Postoperative care:}

At the day of the surgery patients were instructed for cold application to reduce post-operative edema. All patients were dismissed after prescription of Chlorhexidine mouth wash 3 times a day for 2 weeks post- operatively. This was accompanied by Augmentin antibiotic (amoxycillin + clavulanate potassium,GSK) $1 \mathrm{gm}$ b.i.d for 5 days \& Brufen 400mg as anti-inflammatory pain killer. One week postoperative patients were recalled for suture removal.

\section{Follow up:}

During the first month patients were recalled on weekly bases then monthly bases. Each visit included clinical and radiographic evaluation. Clinically the surgical site was examined for signs of soft tissue healing. Radiographic evaluation was utilised for the implant $\&$ the surrounding bone.

\section{Radiological examination:}

The radiographic sweeps were gotten utilizing CBCT Newtom GIANO/VG3-(Quantitative Radiology, Imola, Italy).

According to the CBCT manufacturer recommendations patients were positioned so that the midline laser beam of the CBCT system coordinates to the mid-sagittal plane of the skull and the horizontal laser beam parallel to the occlusal plane.

All Patients received full high resolution scan: Voxel size $0.125 \mathrm{~mm}(10 \mathrm{mAs}, 90 \mathrm{kVp}, 3 \mathrm{~mA})$ and a field of view (FOV) of $80(\mathrm{~mm}) \times 50(\mathrm{~mm}), 360^{\circ}$ rotation around patients in 3.6-second scan time.

Acquired information were changed over into Digital Imaging and Communications in Medicine (DICOM). They were arrange and transported into the product (OnDemand 3D) for volumetric investigation. The pictures were shown in every one of the 3 symmetrical planes (pivotal, coronal, and sagittal). Cross-sectional pictures of the district of intrigue were produced with a pitch separation of $1 \mathrm{~mm}$ and a cut thickness of $1 \mathrm{~mm}$. (Fig $5 \mathrm{~A}, \mathrm{~B}$ )

\section{Implant stability measurement:}

Resonance Frequency Analysis (Osstell ISQ) was utilized for measurement of implant stability on intervals of three and six months for all implants postoperatively. Smartpegs transducers were mounted to the implants to be used with the Osstell device for implant stability measurements. Resonance Frequency (RF) values were measured in four directions representing buccal, palatal, mesial and distal side of the implant. Values were described by a numerical unit called the implant stability quotient (ISQ). (Fig 6) The results were 
presented in ISQ and the mean values for each implant was calculated.

\section{Statistical analysis:}

Collected data were statistically analysed using SPSS ver. 22 software (statistical package for social science on windows 2013) with probability value $\mathrm{p} \leq 0.05$. Changes in preoperative and postoperative data regarding bone density \& implant stability in the same group were evaluated using the Student T test (paired and unpaired) to assess the significance of the difference. The groups were then compared to each other similarly using the Student T test (paired and unpaired).

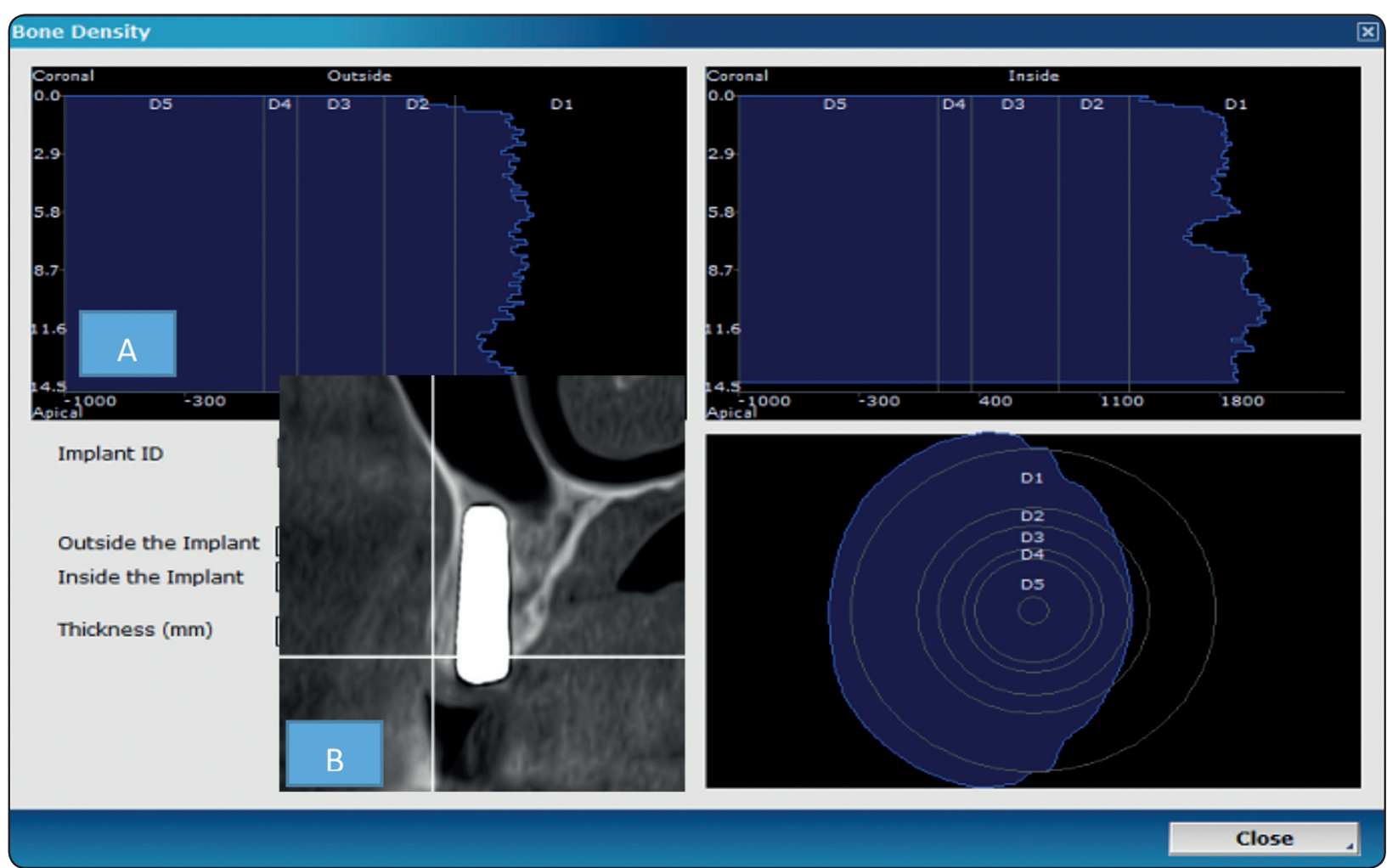

Fig. 5 (A,B) : Showing radiographic verification prior implant placement \& measurement of bone density.

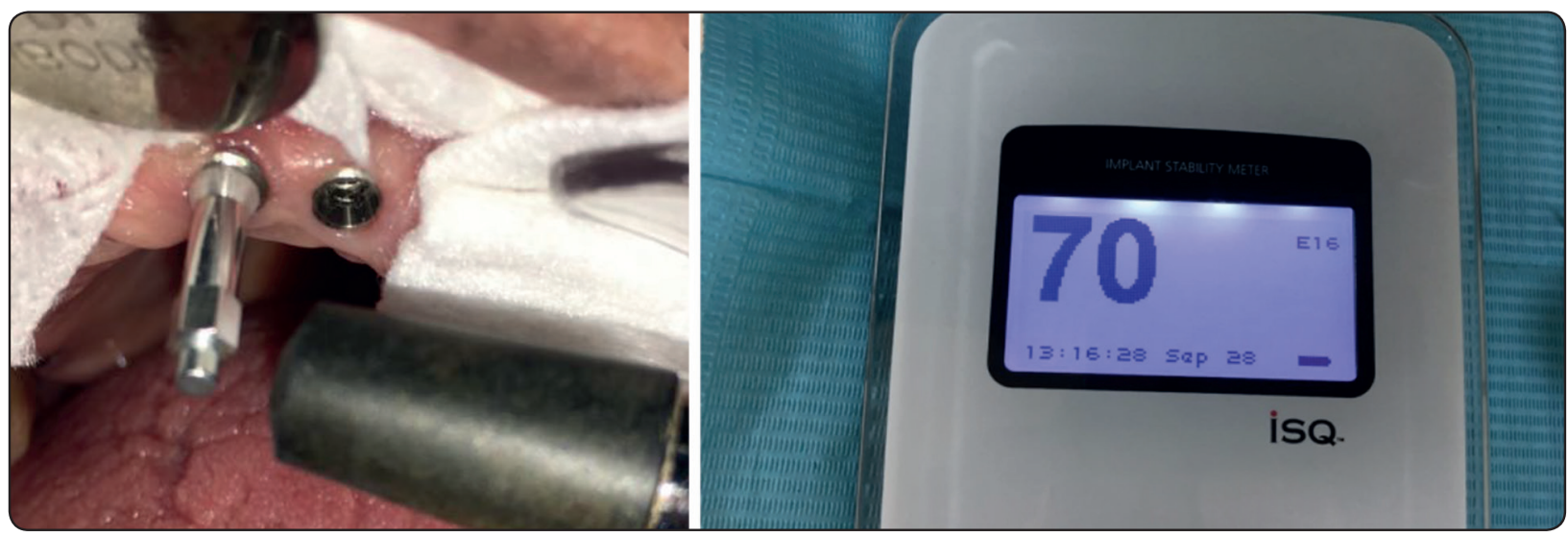

Fig. (6) Showing measurement of implant stability using Osstell device. 


\section{RESULTS}

The current study was conducted to evaluate the influence of varying grafting materials on implant stability \& bone regeneration with immediate implants. Three grafting materials were compared: autogenous bone graft, mineralized plasmatic matrix MPM \& Nano- hydroxyapatite bone graft. Total of fourteen patients with eighteen immediate implants were included. All were assessed clinically \& radiographically for 6 months following implant placement. Neither complications nor clinical side effects were reported from the use of any of the grafting material. All participants showed uneventful healing of hard \& soft tissues throughout the study intervals.

\section{Implant stability:}

\section{Control autogenous bone group}

The Mean Implant Stability Quotients (ISQs) were $(68.00 \pm 4.43)$ at three months and increased to $(75.00 \pm 6.07)$ at six months postoperatively. The records showed significant increase of implant stability $(\mathrm{P} \leq 0.05)$. Table (1)

\section{Study group A (MPM)}

The Mean Implant Stability Quotients (ISQs) were $(66.17 \pm 4.40)$ at three months and increased to $(\mathbf{7 2 . 3 3} \pm \mathbf{5 . 5 7})$ at six months postoperatively. However this increase was statistically nonsignificant $(\mathrm{P} \leq 0.05)$. Table (2)

\section{Study group B (Nano bone)}

The Mean Implant Stability Quotients (ISQs) were $(66.67 \pm 4.41)$ at three months and increased to $(\mathbf{7 3 . 5 0 \pm} \mathbf{5 . 7 5})$ at six months postoperatively. This increase was statistically significant $(\mathrm{P} \leq 0.05)$. Table (3)

When the three groups were compared to each other the variation between them was statistically non-significant $(P \leq 0.05)$ at three and six months post operatively.(Fig 7)
TABLE (1) Showing means of implants stability measurements of the Control autogenous bone group

\begin{tabular}{|c|c|c|}
\cline { 2 - 3 } Implant stability & & \\
\hline Implants & $\begin{array}{c}\text { 3 months post- } \\
\text { operative }\end{array}$ & $\begin{array}{c}\text { 6 months post- } \\
\text { operative }\end{array}$ \\
\hline 1 & 66 & 70 \\
\hline 2 & 74 & 80 \\
\hline 3 & 61 & 65 \\
\hline 4 & 67 & 78 \\
\hline 5 & 70 & 79 \\
\hline 6 & 70 & 78 \\
\hline Mean & $\mathbf{6 8 . 0 0}$ & $\mathbf{7 5 . 0 0}$ \\
\hline SD & $\mathbf{4 . 4 3}$ & $\mathbf{6 . 0 7}$ \\
\hline Min & $\mathbf{6 1 . 0 0}$ & $\mathbf{6 5 . 0 0}$ \\
\hline Max & $\mathbf{7 4 . 0 0}$ & $\mathbf{8 0 . 0 0}$ \\
\hline
\end{tabular}

TABLE (2) Showing means of implants stability measurements of the Study group A (MPM)

\begin{tabular}{|c|c|c|}
\hline Implant stability & & \\
\hline Implants & $\begin{array}{c}3 \text { months post- } \\
\text { operative }\end{array}$ & $\begin{array}{c}6 \text { months post- } \\
\text { operative }\end{array}$ \\
\hline 1 & 64 & 68 \\
\hline 2 & 72 & 77 \\
\hline 3 & 59 & 63 \\
\hline 4 & 66 & 75 \\
\hline 5 & 68 & 75 \\
\hline 6 & 68 & 76 \\
\hline Mean & 66.17 & 72.33 \\
\hline SD & 4.40 & 5.57 \\
\hline Min & 59.00 & 63.00 \\
\hline Max & 72.00 & 77.00 \\
\hline
\end{tabular}


TABLE (3) Showing means of implants stability measurements of the Study group B (Nano bone)

\begin{tabular}{|c|c|c|}
\hline Implant stability & & \\
\hline Implants & $\begin{array}{c}3 \text { months post- } \\
\text { operative }\end{array}$ & $\begin{array}{c}6 \text { months post- } \\
\text { operative }\end{array}$ \\
\hline 1 & 65 & 69 \\
\hline 2 & 73 & 79 \\
\hline 3 & 60 & 64 \\
\hline 4 & 65 & 77 \\
\hline 5 & 68 & 76 \\
\hline 6 & 69 & 76 \\
\hline Mean & 66.67 & 73.50 \\
\hline $\mathrm{SD}$ & 4.41 & 5.75 \\
\hline Min & 60.00 & 64.00 \\
\hline Max & 73.00 & 79.00 \\
\hline
\end{tabular}

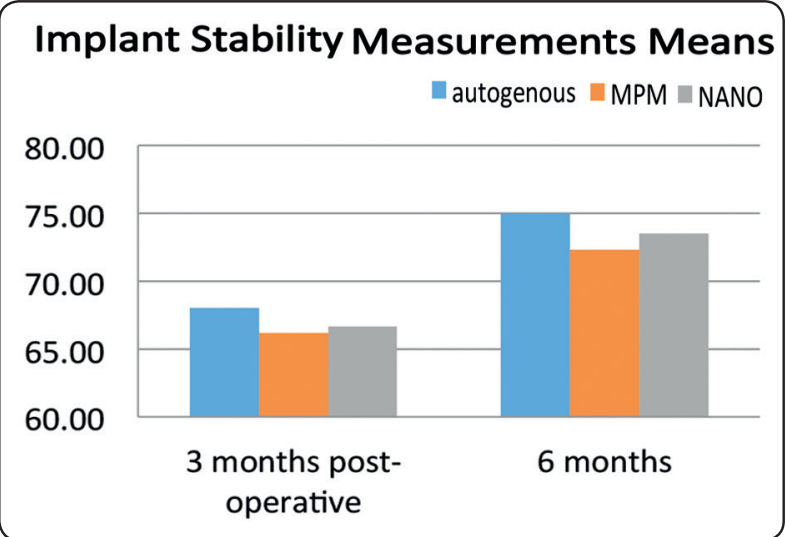

Fig. (7) Showing means of the implants stability measurements of the three groups at 3 and 6 months postoperatively.

\section{Bone Density:}

\section{Control autogenous bone group}

Bone density revealed steady increase from ( $980.83 \pm 27.43 \mathrm{HU})$ at two weeks postoperatively to

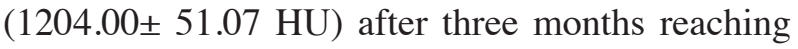
$(1393.33 \pm 33.30 \mathrm{HU})$ after six months showing significant increase in the three records. $(P \leq 0.05)$. Table (4)

\section{Study group A (MPM)}

Bone density revealed significant increase $(\mathrm{P} \leq 0.05)$ at three months postoperatively reaching $(1155.83 \pm 47.88 \mathrm{HU})$ when compared to two weeks records $(871.00 \pm 45.88 \mathrm{HU})$ while at six months postoperative interval a significant decrease $(\mathrm{P} \leq 0.05)$ at the bone density measurements was recorded $(703.17 \pm 43.01 \mathrm{HU})$ in comparison to the three months postoperative data. Table (5)

\section{Study group B (Nano bone)}

Similar to group A bone density showed significant increase $(\mathrm{P} \leq 0.05)$ at three months postoperatively $(1034.50 \pm 75.15 \mathrm{HU})$ in comparison to two weeks interval $(881.17 \pm 31.32 \mathrm{HU})$ \& significant decrease $(\mathrm{P} \leq 0.05)$ of bone density measurements at six months postoperatively $(781.83 \pm 46.84 \mathrm{HU})$ in comparison to the three months postoperative record. Table (6)

When the three groups were compared to each other there was significant difference $(\mathrm{P} \leq 0.05)$ between the control autogenous bone group and the two other groups (MPM \&Nano bone) at all time intervals. Comparison between the Study groups revealed non-significant difference $(\mathrm{P} \leq 0.05)$ between (MPM \& Nano bone) at two weeks interval. While at three \& six months postoperatively there was a significant difference ( $\mathrm{P} \leq 0.05$ between the two groups. (Fig 8)

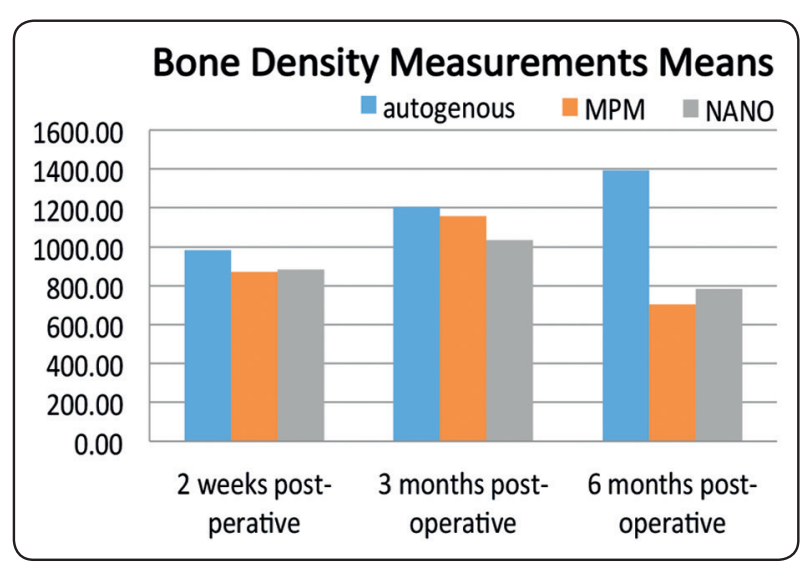

Fig. (8) Showing means of bone density measurements of the three groups at different time intervals. 
TABLE (4) Showing means of bone density measurements of the Control autogenous bone group

\begin{tabular}{|c|c|c|c|}
\hline Bone density & & \\
\hline Implants & 2 weeks post-operative & 3 months post-operative & 6 months post-operative \\
\hline 1 & 982 & 1248 & 1410 \\
\hline 2 & 1032 & 1282 & 1449 \\
\hline 3 & 964 & 1174 & 1382 \\
\hline 4 & 976 & 1190 & 1373 \\
\hline 5 & 952 & 1144 & 1353 \\
\hline 6 & 979 & 1186 & $\mathbf{1 3 9 3 . 3 3}$ \\
\hline Mean & $\mathbf{9 8 0 . 8 3}$ & $\mathbf{1 2 0 4 . 0 0}$ & $\mathbf{3 3 . 3 0}$ \\
\hline SD & $\mathbf{2 7 . 4 3}$ & $\mathbf{5 1 . 0 7}$ & $\mathbf{1 3 5 3 . 0 0}$ \\
\hline Min & $\mathbf{9 5 2 . 0 0}$ & $\mathbf{1 1 4 4 . 0 0}$ & $\mathbf{1 4 4 9 . 0 0}$ \\
\hline Max & $\mathbf{1 0 3 2 . 0 0}$ & $\mathbf{1 2 8 2 . 0 0}$ \\
\hline
\end{tabular}

TABLE (5) Showing means of bone density measurements of the Study group A (MPM)

\begin{tabular}{|c|c|c|c|}
\hline Bone density & & & \\
\hline Implants & 2 weeks post-operative & 3 months post-operative & 6 months post-operative \\
\hline 1 & 894 & 1179 & 722 \\
\hline 2 & 891 & 1176 & 719 \\
\hline 3 & 906 & 1190 & 664 \\
\hline 4 & 814 & 1094 & 743 \\
\hline 5 & 910 & 1200 & 636 \\
\hline 6 & 811 & 1096 & $\mathbf{7 0 3 . 1 7}$ \\
\hline Mean & $\mathbf{8 7 1 . 0 0}$ & $\mathbf{1 1 5 5 . 8 3}$ & $\mathbf{4 3 . 0 1}$ \\
\hline SD & $\mathbf{4 5 . 8 8}$ & $\mathbf{4 7 . 8 8}$ & $\mathbf{6 3 6 . 0 0}$ \\
\hline Min & $\mathbf{8 1 1 . 0 0}$ & $\mathbf{1 0 9 4 . 0 0}$ & $\mathbf{7 4 3 . 0 0}$ \\
\hline Max & $\mathbf{9 1 0 . 0 0}$ & $\mathbf{1 2 0 0 . 0 0}$ & \\
\hline
\end{tabular}

TABLE (6) Showing means of bone density measurements of the Study group B (Nano bone)

\begin{tabular}{|c|c|c|c|}
\hline Bone density & & & \\
\hline Implants & 2 weeks post-operative & 3 months post-operative & 6 months post-operative \\
\hline 1 & 874 & 1019 & 754 \\
\hline 2 & 853 & 1008 & 748 \\
\hline 3 & 913 & 1183 & 838 \\
\hline 4 & 843 & 973 & 742 \\
\hline 5 & 883 & 997 & 845 \\
\hline 6 & 921 & 1027 & $\mathbf{7 8 1 . 8 3}$ \\
\hline Mean & $\mathbf{8 8 1 . 1 7}$ & $\mathbf{1 0 3 4 . 5 0}$ & $\mathbf{4 6 . 8 4}$ \\
\hline SD & $\mathbf{3 1 . 3 2}$ & $\mathbf{7 5 . 1 5}$ & $\mathbf{7 4 2 . 0 0}$ \\
\hline Min & $\mathbf{8 4 3 . 0 0}$ & $\mathbf{9 7 3 . 0 0}$ & $\mathbf{8 4 5 . 0 0}$ \\
\hline Max & $\mathbf{9 2 1 . 0 0}$ & $\mathbf{1 1 8 3 . 0 0}$ & \\
\hline
\end{tabular}


TABLE (7) Correlation between implant stability and bone density was statically significant in the three groups at all intervals of the study with $(\mathrm{P} \leq 0.05)$ except at three months postoperatively of autogenous group.

\begin{tabular}{|c|c|c|c|c|c|c|c|c|}
\hline & \multicolumn{2}{|c|}{} & \multicolumn{2}{|c|}{ Implant stability } & \multicolumn{2}{c|}{$\begin{array}{c}\text { Correlations between } \\
\text { HU and ISQ } \\
\text { At three months }\end{array}$} & \multicolumn{2}{c|}{$\begin{array}{c}\text { Correlations between } \\
\text { HU and ISQ } \\
\text { At six months }\end{array}$} \\
\cline { 2 - 11 } & $\begin{array}{c}3 \text { months } \\
\text { post- } \\
\text { operative }\end{array}$ & $\begin{array}{c}6 \text { months } \\
\text { post- } \\
\text { operative }\end{array}$ & $\begin{array}{c}3 \text { months } \\
\text { post- } \\
\text { operative }\end{array}$ & $\begin{array}{c}6 \text { months } \\
\text { post- } \\
\text { operative }\end{array}$ & r value & P value & r value & P value \\
\hline Autogenous group & 1204.00 & 1393.33 & 68.00 & 75.00 & 0.39 & 0.06 & 0.084 & 0.003 \\
\hline MPM Group & 1155.83 & 703.17 & 66.17 & 72.33 & 0.19 & 0.02 & 0.46 & 0.02 \\
\hline Nano GROUP & 1034.50 & 781.83 & 66.67 & 73.50 & 0.66 & 0.01 & 0.46 & 0.02 \\
\hline
\end{tabular}

\section{DISCUSSION}

With the advent of immediate implant dentistry, their use became a legitimate treatment modality. Authors recommended grafting per -implant gap that exceeds $1-2 \mathrm{~mm}$ to minimize post-operative bone resorption and enhance aesthetic soft tissue healing. ${ }^{(31,32,33,34)}$ yet the influence of the grafting procedure on implant stability has not been comprehended.

Autogenous bone graft is considered as the golden standard for grafting materials owing to it is unique osteogenic properties. However, the encountered donor site morbidity \& limitation on the obtained quantity encourage operators to use other types of grafting materials. ${ }^{(35)}$ A variety of bone substitutes were developed to overcome the possible limitations of autogenous bone graft. ${ }^{(36)}$ Recently many allogeneic, alloplastic, and xenogeneic bone graft materials are projected, based on completely different biological mechanisms and bone regeneration principles, like tissue engineering, and therefore the osteoinductive and osteoconductive potential of various scaffolds. ${ }^{(37)}$

Recently autologous blood product rich in growth factors and platelets are increasingly used to enhance biological characteristics and success rate of the graft. ${ }^{(38)}$ Ever since the developed PRF as the second generation of platelets concentrate the application of this material in regenerative implant dentistry has revolutionized greatly. (39) This is explained by its distinctive criteria being entirely autologous formulated without the addition of anticoagulant which is buns over the Platelets Reach Plasma PRP the first generation of platelet concentrate. ${ }^{(40)}$ MPM was introduced as natural advancement of platelet rich plasma. (41) The material has distinctive structure composed of two phases. Plasmatic phase collected following blood centrifugation \& mineralised phase composed of any bone graft (autogenous, allogenic, xenogeneic or synthetic bone substitute). The resulting mixture showed great capacity to improve healing of hard \& soft tissue accomplished by the release of growth factors from entrapped platelets in the fibrin network. ${ }^{(42)}$ Meanwhile, The mineral phase provides a scaffold for bone cells with its osteoconductive effect. ${ }^{(38)}$ With its unique mechanical \& biological behaviour MPM was utilized by many researchers to enhance bone regeneration. ${ }^{(21,38,43,44,19,45)}$

Recently developed synthetic bone substitute consists of Nano-crystalline hydroxyapatite (HA) and Nano-structured silica (SiO2). The osteoconductive \& biodegradable behaviour of the material was described to be similar to the remodelling processes occurring in natural 
bone. ${ }^{(46)}$ Pezzatini et al. reported that the material has proangiogenic potential related to the structure of hydroxyapatite nanocrystals which induces the release of vascular endothelial growth factor that in turn results in improved bone formation. (47) Clinical \& experimental studies have demonstrated the enhanced regenerative effect of the nanobone graft. ${ }^{(48-52)}$

In the present study we evaluated the efficacy of two currently available grafting materials (MPM\& Nano Bone) in comparison to the autogenous bone graft. The mean Implant Stability Quotients (ISQs) and bone density around the implants were compared. Our results demonstrate that although autogenous bone graft showed higher values of (ISQs) both at three \& six months post-operative intervals, yet the variation was statistically non-significant $(\mathrm{P} \leq 0.05)$. This suggests that the currently tested materials can be used as a possible alternative to autogenous bone eliminating the risk of complications encountered with it.

The mean values of (ISQs) recorded in the present study are comparable to Kang et al . ${ }^{(53)}$ study that evaluated stability of simultaneously placed dental implants with autologous bone grafts harvested from the iliac crest or intraoral jaw bone. The mean ISQ value was $69 \pm 9$ for intraoral group and 71 \pm 10 for iliac crest counterpart with no statistical difference between the two groups. On the other hand, Gangwar, et al. ${ }^{(54)}$ reported implant stability value of 75.71 ISQ for implants with PRGF. Results of ISQ were comparable as well to values reported by Canullo et al $^{(55)}$ that reported ISQ of 66.61 (SD: 4.76) at three months interval for implants placed simultaneously with sinus lifting using nanocrystalline hydroxyapatite sole bone filler.

In the current study when the three grafting materials were evaluated for their influence on bone density; they all showed significant increase $(\mathrm{P} \leq 0.05)$ of density values at three months post operatively. However, autogenous bone group showed higher values of bone density with significant difference $(\mathrm{P} \leq 0.05)$ when compared to MPM \& Nano-bone at all time intervals. On the other hand when MPM \& Nano-bone were compared they revealed non-significant difference $(\mathrm{P} \leq 0.05)$ at two weeks interval. While at three \& six months postoperatively there was a significant difference $(\mathrm{P} \leq 0.05)$ between the two groups.

Current results are comparable to findings reported by Turkyilmaz et al. $\left(^{56}\right)$ that showed bone density values of $721 \pm 254 \mathrm{HU}$ at implant sites. As well as reports by Arisan et al. ${ }^{(57)}$ that revealed values of gray density to be $(765 \pm 97.32$ voxel value) using CBCT based values and $(668.4 \pm 110$ Hounsfield unit) using CT-based values.

In the present study the correlation between implant stability and bone density was statically significant in the three groups at all intervals of the study except at three months postoperatively of autogenous group.

These results were comparable to aforementioned studies. ${ }^{(56,57)}$

\section{CONCLUSION}

The use of different grafting materials to fill the gap around immediate implants enhances implant stability and bone density. Yet the autogenous bone graft remains the golden standard for grafting materials, but the current study showed the possibility of using MPM or Nano-Graft materials with successful outcomes as well regarding implant stability and bone density.

\section{REFERENCES}

1. Albrektsson T, Brånemark PI, Hansson HA LJ . Osseointegrated dental implants. Bionic Hum Heal Promot People With Implant Prosthet Devices. 1981:155-170. doi:10.1007/978-1-59259-975-2_45

2. Brånemark P I, Svensson B, Van Steenberghe D. Ten-year survival rates of fixed prostheses on four or six implants ad modum Brånemark in full edentulism. Clin Oral Implants Res. 1995;6(4):227-231. doi:10.1034/j.16000501.1995.060405.x 
3. Becker W. Immediate implant placement: treatment planning and surgical steps for successful outcomes. $\mathrm{Br}$ Dent J. 2006;201(4):199-205. doi:10.1038/sj.bdj.4813881

4. Rosenquist B, Ahmed M. The immediate replacement of teeth by dental implants using homologous bone membranes to seal the sockets: Clinical and radiographic findings. Clin Oral Implants Res. 2000;11(6):572-582. doi:10.1034/j.1600-0501.2000.011006572.x

5. Malo P, Friberg B, Polizzi G, Gualini F, Vighagen T, Rangert B. Immediate and early function of Branemark System implants placed in the esthetic zone: a 1-year prospective clinical multicenter study. Clin Implant Dent Relat Res. 2003;5 Suppl 1:37-46.

6. Kim D-W, Heo H-A, Lim S-G, Lee W, Kim Y-S, Pyo $\mathrm{S}-\mathrm{W}$. Bone response around immediately placed titanium implant in the extraction socket of diabetic and insulintreated rat maxilla. J Korean Assoc Oral Maxillofac Surg. 2011;37(1):30. doi:10.5125/jkaoms.2011.37.1.30

7. Kan JY, Rungcharassaeng K. Immediate placement and provisionalization of maxillary anterior single implants: a surgical and prosthodontic rationale. Pract Periodontics Aesthet Dent. 2000;12(9):817-24; quiz 826. doi:10.1016/ B978-1-4557-4476-3.00008-1

8. Esposito M, Grusovin MG, Willings M, Coulthard P, Worthington H V. The effectiveness of immediate, early, and conventional loading of dental implants: a Cochrane systematic review of randomized controlled clinical trials. Int J Oral Maxillofac Implants. 2007;22(6):893-904.

9. Tan WL, Wong TLT, Wong MCM, Lang NP. A systematic review of post-extractional alveolar hard and soft tissue dimensional changes in humans. Clin Oral Implants Res. 2012;23(SUPPL. 5):1-21. doi:10.1111/j.16000501.2011.02375.x

10. Schropp L. Bone healing and soft tissue contour changes following single-tooth extraction: A clinical and radiographic 12-month prospective study. J Prosthet Dent. 2004;91(1):92. doi:10.1016/j.prosdent.2003.10.022

11. Vignoletti F, Sanz M. Immediate implants at fresh extraction sockets: From myth to reality. Periodontol 2000. 2014;66(1):132-152. doi:10.1111/prd.12044

12. Chen ST, Darby IB, Reynolds EC. A prospective clinical study of non-submerged immediate implants: Clinical outcomes and esthetic results. Clin Oral Implants Res. 2007;18(5):552-562. doi:10.1111/j.16000501.2007.01388.x
13. Cardaropoli D, Tamagnone L, Roffredo A, Gaveglio L. Soft Tissue Contour Changes at Immediate Postextraction Single-Tooth Implants with Immediate Restoration: A 12-Month Prospective Cohort Study. Int J Periodontics Restor Dent. 2015;35(2):191-198. doi:10.11607/prd.2326

14. Araújo MG, Linder E, Lindhe J. Bio-Oss ${ }^{\circledR}$ Collagen in the buccal gap at immediate implants: A 6-month study in the dog. Clin Oral Implants Res. 2011;22(1):1-8. doi:10.1111/ j.1600-0501.2010.01920.x

15. Chen S, Buser D. Esthetic Outcomes Following Immediate and Early Implant Placement in the Anterior Maxilla-A Systematic Review. Int J Oral Maxillofac Implants. 2014;29 (Supplement):186-215. doi:10.11607/jomi. 2014 suppl.g3.3

16. Shimazu C, Hara T, Kinuta Y, et al. Enhanced vertical alveolar bone augmentation by recombinant human bone morphogenetic protein-2 with a carrier in rats. $\mathrm{J}$ Oral Rehabil. 2006;33(8):609-618. doi:10.1111/j.13652842.2005.01593.x

17. Anitua E. Plasma rich in growth factors: preliminary results of use in the preparation of future sites for implants. Int J Oral Maxillofac Implants. 1999;14:529-535.

18. Thorat M, Pradeep AR, Pallavi B. Clinical effect of autologous platelet-rich fibrin in the treatment of intra-bony defects: A controlled clinical trial. J Clin Periodontol. 2011;38(10):925-932. doi:10.1111/j.1600051X.2011.01760.x

19. Nadon F, Chaput B, Perisse J, De Berail A, Lauwers F, Lopez R. Interest of mineralized plasmatic matrix in secondary autogenous bone graft for the treatment of alveolar clefts. J Craniofac Surg. 2015;26(7):2148-2151. doi:10.1097/SCS.0000000000001951

20. Boora P, Rathee M, Bhoria M. Effect of Platelet Rich Fibrin (PRF) on peri-implant soft tissue and crestal bone in onestage implant placement: A randomized controlled trial. J Clin Diagnostic Res. 2015;9(4):ZC18-ZC21. doi:10.7860/ JCDR/2015/12636.5788

21. Amine K, Gharibi A, Hsaine A, Kissa J. Effect of Bone Regeneration with Mineralized Plasmatic Matrix for Implant Placement in Aesthetic Zone. Case Rep Dent. 2017;2017:581-591. doi:10.1155/2017/2639564

22. Tabrizi R, Arabion H, Karagah T. Does platelet-rich fibrin increase the stability of implants in the posterior of the maxilla? A split-mouth randomized clinical trial. Int $\mathrm{J}$ Oral Maxillofac Surg. 2018;47(5):672-675. doi:10.1016/j. ijom.2017.07.025 
23. Khojasteh A, Eslaminejad MB, Nazarian $\mathrm{H}$, et al. Vertical Bone Augmentation With Simultaneous Implant Placement Using Particulate Mineralized Bone and Mesenchymal Stem Cells: A Preliminary Study in Rabbit. J Oral Implantol. 2013;39(1):3-13. doi:10.1563/AAIDJOI-D-10-00206

24. Canullo L, Dellavia C. Sinus lift using a nanocrystalline hydroxyapatite silica gel in severely resorbed maxillae: Histological preliminary study. Clin Implant Dent Relat Res. 2009;11(SUPPL. 1):7-13. doi:10.1111/j.17088208.2008.00141.x

25. Hossein Fathi M, Mortazavi V, Roohani Esfahani SI. Bioactivity Evaluation of Synthetic Nanocrystalline Hydroxyapatite. Dent Res J (Isfahan). 2009;5(2):81-87.

26. Wang Y-F, Wang C-Y, Wan P, Wang S-G, Wang X-M. Comparison of bone regeneration in alveolar bone of dogs on mineralized collagen grafts with two composition ratios of nano-hydroxyapatite and collagen. Regen Biomater. 2016;3(1):33-40. doi:10.1093/rb/rbv025

27. Alagl AS, Madi M. Localized ridge augmentation in the anterior maxilla using titanium mesh, an alloplast, and a nano-bone graft: a case report. J Int Med Res. 2018;46(5):2001-2007. doi:10.1177/0300060518758226

28. Dayashankar C, Deepika P, Siddaramaiah B. Clinical and radiographic evaluation of citric acid-based nano hydroxyapatite composite graft in the regeneration of intrabony defects - A randomized controlled trial. Contemp Clin Dent. 2017. doi:10.4103/ccd.ccd_213_17

29. Sadeghi R, Najafi M, Semyari H, et al. The Effects of Hydroxyapatite-Chitosan Membrane on Bone Regeneration in Rat Calvarial Defects. J Korean Acad Periodontol. 2018;39(1):832-836. doi:10.1111/cid.12598

30. Dohan DM, Choukroun J, Diss A, et al. Platelet-rich fibrin (PRF): A second-generation platelet concentrate. Part II: Platelet-related biologic features. Oral Surgery, Oral Med Oral Pathol Oral Radiol Endodontology. 2006;101(3). doi:10.1016/j.tripleo.2005.07.009

31. Araújo MG, Wennström JL, Lindhe J. Modeling of the buccal and lingual bone walls of fresh extraction sites following implant installation. Clin Oral Implants Res. 2006;17(6):606-614. doi:10.1111/j.16000501.2006.01315.x

32. Chen ST, Buser D. Clinical and esthetic outcomes of implants placed in postextraction sites. Int $\mathrm{J}$ Oral Maxillofac Implants. 2009;24 Suppl:186-217.
33. Spinato S, Agnini A, Chiesi M, Agnini AM, Wang HL. Comparison between graft and no-graft in an immediate placed and immediate nonfunctional loaded implant. Implant Dent. 2012;21(2):97-103. doi:10.1097/ ID.0b013e318248866c

34. Harel N, Moses O, Palti A, Ormianer Z. Long-Term Results of Implants Immediately Placed Into Extraction Sockets Grafted With $\beta$-Tricalcium Phosphate: A Retrospective Study. J Oral Maxillofac Surg. 2013;71(2):e63-e68. doi:10.1016/j.joms.2012.09.022

35. Betz RR. Limitations of autograft and allograft: new synthetic solutions. Orthopedics. 2002;25(5 Suppl):s561-70.

36. Aghaloo TL, Moy PK. Which hard tissue augmentation techniques are the most successful in furnishing bony support for implant placement? Int J Oral Maxillofac Implants. 2007;22 Suppl:49-70.

37. McAllister BS, Haghighat K. Bone Augmentation Techniques. J Periodontol. 2007;78(3):377-396. doi:10.1902/ jop.2007.060048

38. Samir E, Hicham S, Keltoum EO, Zouheir I. Management of post-extractional alveolar socket with mineralized plasmatic matrix before implant placement: a case report. Asian Pacific J Heal Sci. 2017;4(3):220-227. doi:10.21276/ apjhs.2017.4.3.33

39. Dohan DM, Choukroun J, Diss A, et al. Platelet-rich fibrin (PRF): A second-generation platelet concentrate. Part I: Technological concepts and evolution. Oral Surgery, Oral Med Oral Pathol Oral Radiol Endodontology. 2006;101(3). doi:10.1016/j.tripleo.2005.07.008

40. Passaretti F, Tia M, D'esposito V, et al. Growth-promoting action and growth factor release by different platelet derivatives. Platelets. 2014;25(4):252-256. doi:10.3109/0 9537104.2013.809060

41. Mazzoni L, Périssé J. Apports de la microscopie électronique à Balayage pour la Matrice Plasmatique Minéralisée. La Lett la Stomatol. 11.

42. Elmoheb M. The Use of Growth Factors Fibrin Network to Enhance Architecture, Mechanical and Biological Aspect of the Graft Particles. I J Pre Clin Dent Res. 2014;1(2):41-44.

43. Report C. Localized Maxillary Ridge Augmentation with Mineralized Plasmatic Matrix for Dental Implant Placement. 2017;4(June):1-5.

44. Comparative Study Socket Preservation using PRF and MPM Platelets Concentrates. I J Pre Clin Dent Res. 2015;2(5):1-4. 
45. Elbokle NN, Sultan OI, Chehata IM, Hossam AM. Effect of Bone Regeneration with Platelets Rich Fibrin versus Mineralized Plasmatic Matrix for Immediate Implant Placement. EDJ. 63(4):581-591.

46. HenkelKO,GerberT,Lenz S, GundlachKKH,Bienengräber V. Macroscopical, histological, and morphometric studies of porous bone-replacement materials in minipigs 8 months after implantation. Oral Surgery, Oral Med Oral Pathol Oral Radiol Endodontology. 2006;102(5):606-613. doi:10.1016/j.tripleo.2005.10.034

47. Pezzatini S, Morbidelli L, Solito R, et al. Nanostructured HA crystals up-regulate FGF-2 expression and activity in microvascular endothelium promoting angiogenesis. Bone. 2007;41(4):523-534. doi:10.1016/j.bone.2007.06.016

48. Canullo L, Patacchia O, Sisti A, Heinemann F. Implant Restoration 3 Months after One Stage Sinus Lift Surgery in Severely Resorbed Maxillae: 2-Year Results of a Multicenter Prospective Clinical Study. Clin Implant Dent Relat Res. 2012;14(3):412-420. doi:10.1111/j.17088208.2009.00261.x

49. GĂśstz W, Lenz S, Reichert C, et al. A preliminary study in osteoinduction by a nano-crystalline hydroxyapatite in the mini pig. Folia Histochem Cytobiol. 2011;48(4). doi:10.2478/v10042-010-0096-x

50. Gholami GA, Najafi B, Mashhadiabbas F, Goetz W, Najafi S. Clinical, histologic and histomorphometric evaluation of socket preservation using a synthetic nanocrystalline hydroxyapatite in comparison with a bovine xenograft: A randomized clinical trial. Clin Oral Implants Res. 2012;23(10):1198-1204. doi:10.1111/j.1600-0501.2011.02288.x

51. Ghanaati S, Lorenz J, Obreja K, Choukroun J, Landes C, Sader RA. Nanocrystalline Hydroxyapatite-Based Material Already Contributes to Implant Stability After 3 Months: A Clinical and Radiologic 3-Year Follow-up Investigation. J Oral Implantol . 2014;40(1):103-110 . doi:10.1563/AAIDJOI-D-13-00232
52. Ghanaati S, Barbeck M, Willershausen I, et al. Nanocrystalline Hydroxyapatite Bone Substitute Leads to Sufficient Bone Tissue Formation Already after 3 Months: Histological and Histomorphometrical Analysis 3 and 6 Months following Human Sinus Cavity Augmentation. Clin Implant Dent Relat Res. 2013;15(6):883-892. doi:10.1111/j.1708-8208.2011.00433.x

53. Kang YH, Kim HM, Byun JH, et al. Stability of simultaneously placed dental implants with autologous bone grafts harvested from the iliac crest or intraoral jaw bone. BMC Oral Health. 2015;15(1):1-11. doi:10.1186/ s12903-015-0156-x

54. Gangwar S, Pal US, Singh S, Singh RK, Singh V, Kumar L. Immediately placed dental implants in smokers with plasma rich in growth factor versus without plasma rich in growth factor: A comparison. Natl J Maxillofac Surg. 2018;9(1):39-47. doi:10.4103/njms.NJMS_74_17

55. Canullo L, Patacchia O, Sisti A, Heinemann F. Implant Restoration 3 Months after One Stage Sinus Lift Surgery in Severely Resorbed Maxillae: 2-Year Results of a Multicenter Prospective Clinical Study. Clin Implant Dent Relat Res. 2012;14(3):412-420. doi:10.1111/j.17088208.2009.00261.x

56. Turkyilmaz I, Tumer C, Ozbek EN, Tözüm TF. Relations between the bone density values from computerized tomography, and implant stability parameters: a clinical study of 230 regular platform implants. J Clin Periodontol. 2007;34(8):716-722. doi:10.1111/j.1600051X.2007.01112.x

57. Arisan V, Karabuda ZC, Avsever H, Özdemir T. Conventional Multi-Slice Computed Tomography (CT) and Cone-Beam CT (CBCT) for Computer-Assisted Implant Placement. Part I: Relationship of Radiographic Gray Density and Implant Stability. Clin Implant Dent Relat Res. 2013;15(6):893-906. doi:10.1111/j.17088208.2011.00436.x 